IRA-International Journal of Technology \& Engineering

ISSN 2455-4480; Vol.08, Issue 02 (August 2017)

Pg. no. $15-27$

Institute of Research Advances

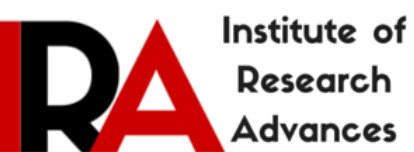

https://research-advances.org/index.php/IRAJTE

\title{
User Mobility Analysis of Lighting Practices in Konya City Square
}

\author{
Bilgehan YILMAZ ÇAKMAK ${ }^{1}$, Hamdi BEKTAS ${ }^{2}$, Serpil SUCUCAN ${ }^{3}$ \\ ${ }^{1}$ Assistant Prof. Dr. Faculty of Architecture, Selcuk University, Konya, Turkey. \\ ${ }^{2}$ Electricity Engineer, Konya Metropolitian Municipality, Department of Construction, Konya, Turkey. \\ ${ }^{3}$ Urban Planner, Konya Metropolitian Municipality, Department of Construction, Konya, Turkey.
}

Type of Review: Peer Reviewed.

DOI: http://dx.doi.org/10.21013/jte.v8.n2.p2

How to cite this paper:
YILMAZ ÇAKMAK, B., BEKTAS, H., SUCUCAN, S. (2017). User Mobility Analysis of Lighting
Practices in Konya City Square. IRA International Journal of Technology \& Engineering (ISSN 2455-4480),
8(2), 15-27. doi:http://dx.doi.org/10.21013/jte.v8.n2.p2

(C) Institute of Research Advances.

\section{(cc) $\mathrm{Br}-\mathrm{NC}$}

This work is licensed under a Creative Commons Attribution-Non Commercial 4.0 International License subject to proper citation to the publication source of the work.

Disclaimer: The scholarly papers as reviewed and published by the Institute of Research Advances (IRA) are the views and opinions of their respective authors and are not the views or opinions of the IRA. The IRA disclaims of any harm or loss caused due to the published content to any party.

Institute of Research Advances is an institutional publisher member of Publishers Inter Linking Association Inc. (PILA-CrossRef), USA. The institute is an institutional signatory to the Budapest Open Access Initiative, Hungary advocating the open access of scientific and scholarly knowledge. The Institute is a registered content provider under Open Access Initiative Protocol for Metadata Harvesting (OAI-PMH).

The journal is indexed \& included in WorldCat Discovery Service (USA), CrossRef Metadata Search (USA), WorldCat (USA), OCLC (USA), Open J-Gate (India), EZB (Germany) Scilit (Switzerland), Airiti (China), Bielefeld Academic Search Engine (BASE) of Bielefeld University, Germany, PKP Index of Simon Fraser University, Canada. 


\begin{abstract}
Aim: There have been many urban design application and research studies describing the connection between user movement and space. The Space Syntax Method, an urban design model developed by the Space Syntax Laboratory at University College London, England, seeks to describe the connection between pedestrian movement and spatial formation on a mathematical basis. The Space Syntax is specialized approach used in designing pedestrian connections within the urban structure. It observes pedestrian and vehicle movements, and uses computer programs to calculate the potential effects of design proposals on pedestrian movement. Method: This model is used in many European countries and it provides consistent results for pedestrian movement. This method was utilized to determine the connection between pedestrian movement and the space format in a field described in this study - the Konya City Square. Starting from pedestrian movement and the assembly points, the study recorded the observations and the follow-up of pedestrian movement in Konya city center during a one-week period (at different hours of the day, on weekdays and weekends, in the daytime and at night). A video recording was made and it was turned into pedestrian movement charts. Graphic maps were also prepared and they were compared to the Space Syntax Method. Furthermore, a lighting analysis was conducted in the City Square using the DIALux lighting calculation program and it was found to be consistent with the current records. Conclusion: The study concluded that the lighting work at the City Square underestimated pedestrian movement on the Square, and the monument at the center of the Square lacked visibility and definability. Suggestions were put forward regarding these issues.
\end{abstract}

Keywords: space syntax, urban lighting, pedestrian movement

\title{
Introduction
}

City phenomenon and lighting are important areas of study for physical and social sciences. Although lighting is a technical issue, it impacts on humans in a broad and general way, from architecture to psychology, from productivity to economy. The term "city", on the other hand, encompasses politics, economy, culture, health and art.

Pedestrian movement and behaviours underlie urban arrangements. Pedestrian movements must be followed and examined, and pedestrian behaviours should be observed at different times and in different situations in order for users to utilize the spaces and the city at optimum levels and establish an ideal connection between the spaces. In this context, while there are some software programs and applications available, managing urban arrangements by observing the spatial and urban behavior of the users is underutilized.

Urban and architectural lighting is a field that reveals and directs user behaviours. Based on accurate and scientific analyses, urban lighting enhances the semantic and functional values of the city and its spaces.

In the context of the connection between user movement and urban lighting, Konya city centre raises some questions. Are the user behaviours on the Square compliant with the Square arrangement? Does the Square transfer the pedestrian axes from the environment to the necessary points? Does the Square lighting direct the pedestrians to the right axes and centres? Is the monument at the centre of the Square visible enough in terms of semantic and functional value? This study seeks answers to these questions.

\subsection{Lighting}

The main purpose in lighting is, according to the definition accepted by the International Commission on Illumination, "to apply light in order to enable the proper visibility of the objects and the environment." If the goal of lighting is, as defined above, to enable visual perception of any object or environment, the key criteria which should be taken into consideration in lighting designs are the quantity of the lighting, the quality of the lighting, luminance and the surface properties (Dokuzcan 2006)

The quantity of the lighting concerns the lighting level. The quality of the lighting is about the distribution of the lighting level, light direction, shadows which are created under lighting and the color of the light (Dokuzcan 2006) 
The area to be lit, the type of the lighting, the physical features, colours, textures, mobility or immobility of the objects or environments, interior or exterior surface, architecture, and smallness or largeness of the space determine the quantity, and therefore quality of the lighting.

To enable people to perform outdoor visual tasks efficiently and accurately, especially during the night, adequate and appropriate lighting has to be provided. The degree of visibility and comfort required in a wide range of outdoor work places is governed by the type and duration of activity. This standard specifies requirements for lighting of tasks in most outdoor work places and their associated areas in terms of quantity and quality of illumination. In addition recommendations are given for good lighting practice. It is important that all clauses of the standard are followed although the specific requirements are tabulated in the schedule of lighting requirements ${ }^{1}$

Good lighting requires equal attention to the quantity and quality of the lighting. While the provision of sufficient illuminance on the task is necessary, in many instances the visibility depends on the way in which the light is delivered, the colour characteristics of the light source and surfaces together with the level of glare from the system. In this standard opportunity was taken to specify for various work places and task types not just the illuminance but also the limiting discomfort glare and minimum colour rendering index of the source. Parameters to create comfortable visual conditions are proposed in the body of this standard. The recommended values are considered to represent a reasonable balance, having regard to the requirements for safe, healthy and efficient work performance. The values can be achieved with practical energy efficient solutions. There are also visual ergonomic parameters such as perceptual ability and the characteristics and attributes of the task, which determine the quality of the operator's visual skills, and hence performance levels. In some cases enhancement of these influencing factors can improve performance without the need to raise illuminance. For example by improving the contrast of the task attributes, enlarging the task by the use of up to date visual aids (glasses) and by the provision of special lighting systems with local directional lighting capability ${ }^{2}$

\subsection{Urban Lighting}

Lighting systems are one of the most significant tools available to modern cities. The purpose of urban lighting is to make cities habitable, day and night, and to reveal the city's values.

Creating urban identity using urban lighting, making the city habitable at night by creating a nighttime image, enabling night tourism, providing better perception of prominent places, indicating historical and architectural heritage, and providing comfort in housing zones all contribute to the development and expansion of cities $^{3}$

Today, city lighting includes not only the illumination of pedestrian paths and traffic byroads, but also the installation of lighting systems that make the city functionally and aesthetically attractive. Lighting important structures, makes the appearance of the part of the city in which they are located more meaningful and effective. The lighting of important city structures helps to determine the characteristics of the city, enabling not only the visibility of the lighted object, but also revealing its architectural features, configuration and function.

Urban lighting is divided into functional lighting and architectural lighting. Functional lighting is subdivided into five categories including security, transportation, playing fields, industrial zones, and trade areas; while architectural lighting is also grouped into five categories including constructions, works of art, works of engineering, landscape architecture and pedestrian areas.

The purpose in functional lighting is to carry out the relevant action in the quickest, best and safest way possible. In this case, the lighting enables safe traffic movement by enhancing the visibility of the roads and environment. In such spaces, it is adequate to install systems which are able to create evenly distributed light as far as possible

\footnotetext{
${ }^{1}$ TS EN 12464-1. Light and lighting - lighting of work places - Part 1: Indoor work places, http://www.fer.unizg.hr/_download/repository/EN_12464-2.pdf

${ }_{2}^{2}$ ISO 8995-1:2002(en) Lighting of work places - Part 1: Indoor

${ }^{3} \mathrm{http} / / / \mathrm{www} . i b b . g o v . t r /$ sites/aydinlatmaenerji/Pages/KentselAydinlatma.aspx
} 
Architectural lighting areas, on the other hand, should target a lighting design prioritizing aesthetics, protecting city-specific local identity and aiming to improving the city's image ${ }^{4}$

\section{MATERIALS AND METHODS}

Many urban design application and research studies have been conducted to describe the connection between user movement and space. The images connected to place includes physical images and features in the minds of users (Özdemir 2016, 43).

The Space Syntax method (Space Syntax), an urban design model developed by the Space Syntax Laboratory at University College London, England, seeks to describe the connection between pedestrian movement and spatial formation on a mathematical basis.

This study employed the Space Syntax Method in the determination of user mobility on Konya City Square. Starting from pedestrian movement and the assembly points, the study recorded the observations and the follow-up of pedestrian movement in Konya city center during a one-week period (at different hours of the day, on weekdays and weekends, in the daytime and at night). A video recording was made and it was turned into pedestrian movements charts. Also, graphic maps were prepared and compared to results of the Space Syntax Method.

Furthermore, a lighting analysis was conducted in the City Square using the Dialux lighting calculation program and it was found to be consistent with the current records.

Helping to objectively define the City Square, the Space Syntax searches for the gathering potential of people, with its claim that there is a direct connection between the space organization and the social structure, by making the "elbow rooms" overlap with fields of vision, particularly in urban outdoor areas(Tuncer 2010). It utilizes:

a) A polygon called isovist, which forms the widest range of view and which is visible from any point;

b) Axial lines, the longest line of sight which is visible from any point and which people use in directing their movements; and

c) Available/functional convex spaces.

This analytical method divides the urban and architectural spaces into two different characteristics, such as integrated or dissociated, as a result of analyzing the topological relationships between those parts, which may be referred to as the description of space based on the human experiences, with the aid of network/graph theory. While the most available places, due to their integrated features, are those where the highest number of people are observed, dissociated spaces are those where the movement inclusion potential is low, as they have a structure disconnected from the whole city or building.

In brief, Space Syntax is an active analytical technique used on a city and building scale to evaluate the social, cultural and the organizational critical design decisions about the space; clarifying the relation between the environmental factors and the crime rate; offering objective computer-aided investigation of the effect of spatial order in offices and research bureaus on labour productivity and creativity; and investigating spatial perception and directivity (Y1lmaz Çakmak 2011).

\section{FIELD WORK}

The area where the former court house and a fairground are located was restored as the "City Square" after the transformation of the fairground into Culture Park. The surrounds of the Square include a tramway stop, historical Konya Street (Sultan Street), Selcuklu Exhibition Center and the Karatay Madrasa. The Selcuklu Civilization Monument is situated in the middle of the Square. As seen in Figure 1 and 2, the Square is located at the junction of the pedestrian axes and at an important point linking the pedestrians who travel on public transportation with the city center.

\footnotetext{
${ }^{4}$ https://prezi.com/cz04pnx7u8wm/aydnlatma-kesin-tanm-ile-nesnelere-cevrelerine-ve-kucu/
} 


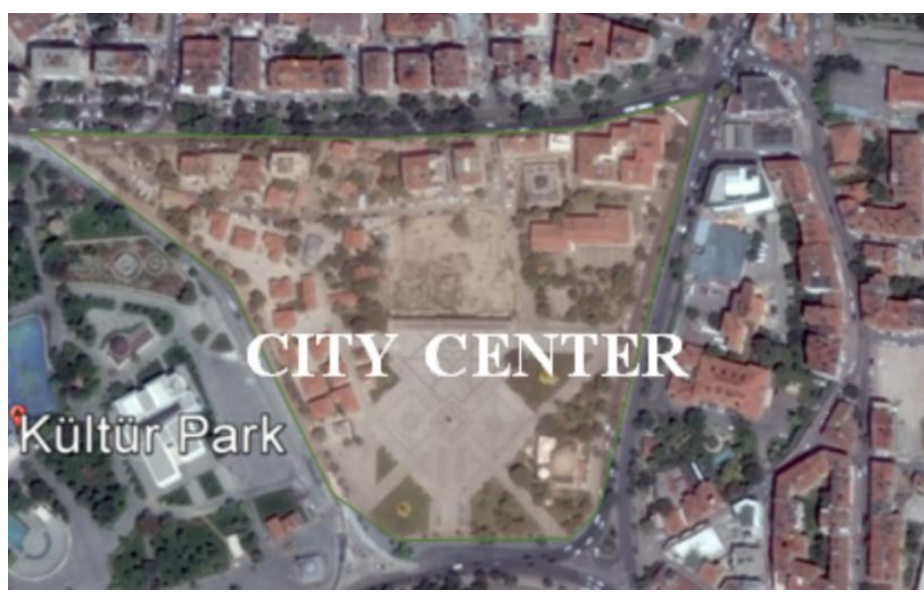

Figure 1: Konya City Square.

Pedestrian axes in the neighbourhood converge on Konya City Square. This is a transition area and an important point linking the city centre with the other areas of the city. Pedestrian approaches in the neighbourhood are observed in Figure 2.

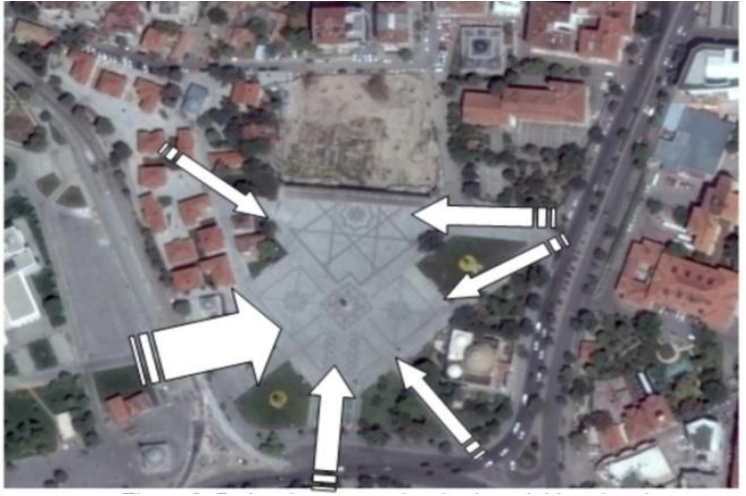

Figure 2: Pedestrian approaches in the neighbourhood.

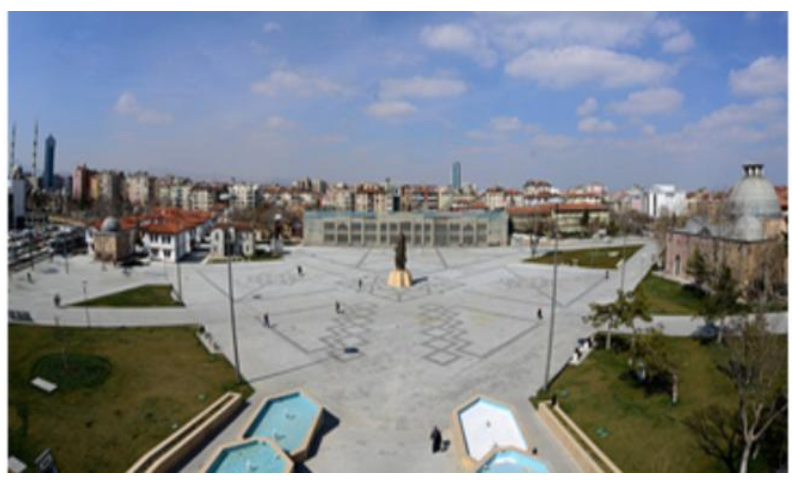

Figure 4: The appearance of Konya City Square.

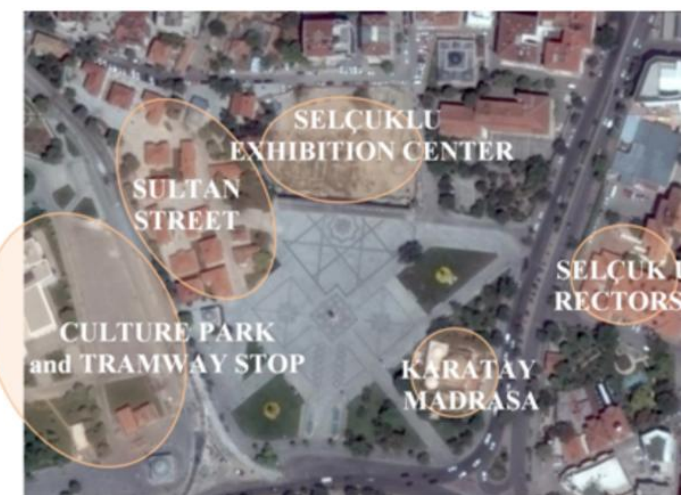

Figure 3: Surrounding structures on the Square

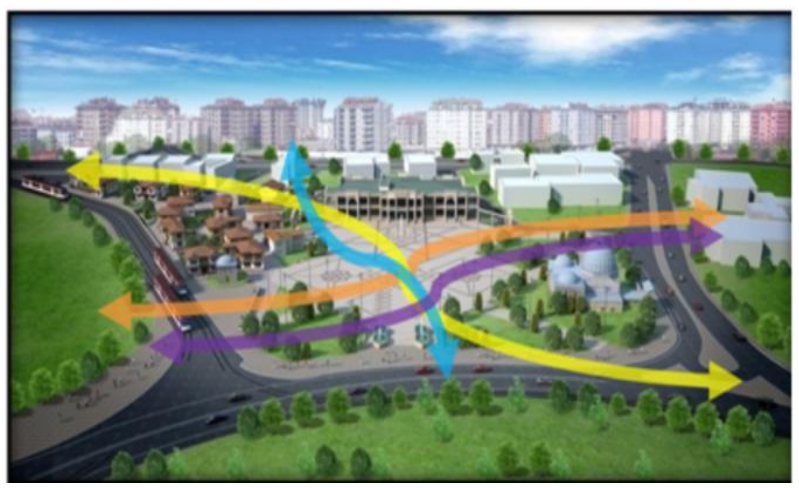

Figure 5: Pedestrian axes passing through City Square.

As seen in Figures 6 and 7, the Selçuklu Civilization Monument is situated at the center of the Konya City Square. The pedestal of the monument forms a triangulation and a focal point in the middle of the Square and is illuminated, but the lighting is inadequate. The semantic value of the monument and the representations on it are not well understood. 

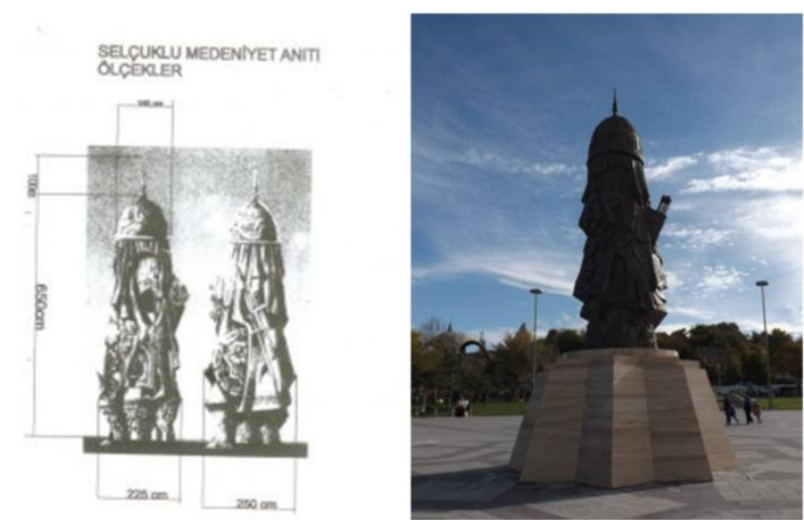

Figure 6: Selçuklu Civilization Monument situated at the center of Konya City Square

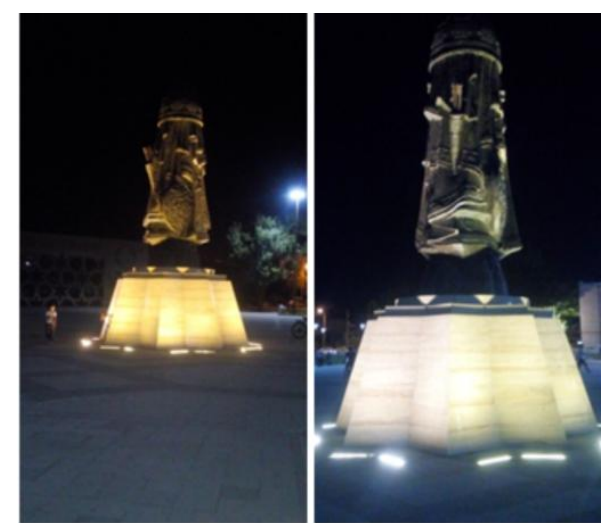

Figure 7: Night lighting of Selçuklu Civilization Monument.

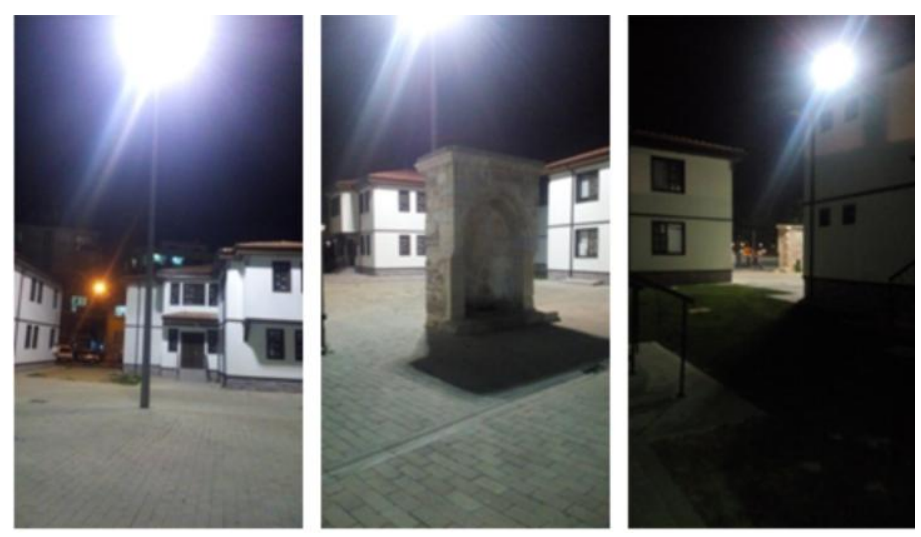

Figure 8: Night lighting of emerging Sultan Street and the fountain.

As seen in Figure 8, Sultan Street, which is a representative form of the traditional Konya street and houses, seems dysfunctional and quiet due to the fact that the construction works have yet to be completed and that each of the houses is in use. Its lighting is excessively intense and eye-straining. In this regard, the strong lighting of the street has lowered the effect of the Square.
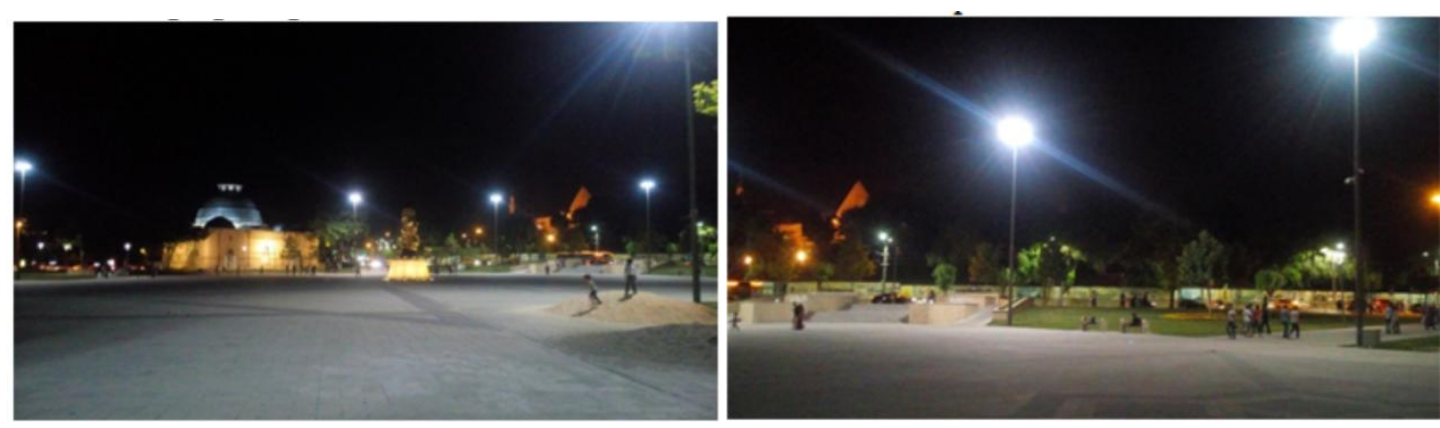

Figure 9, 10: Different views of Konya City Square at night

In Figures 10, 11 and 12, the emerging pedestrian axes and the lighting elements of the Square are observed. Over-dominant and over-strong lighting elements make describing the borders of the Square difficult. The spotlighting with a low routing effect has a high glare effect. 

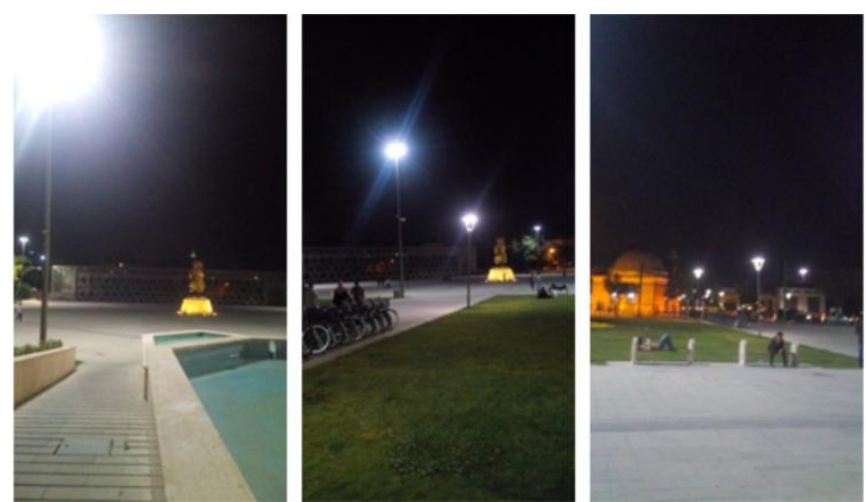

Figure 11: The appearance of the emerging pedestrian axes.
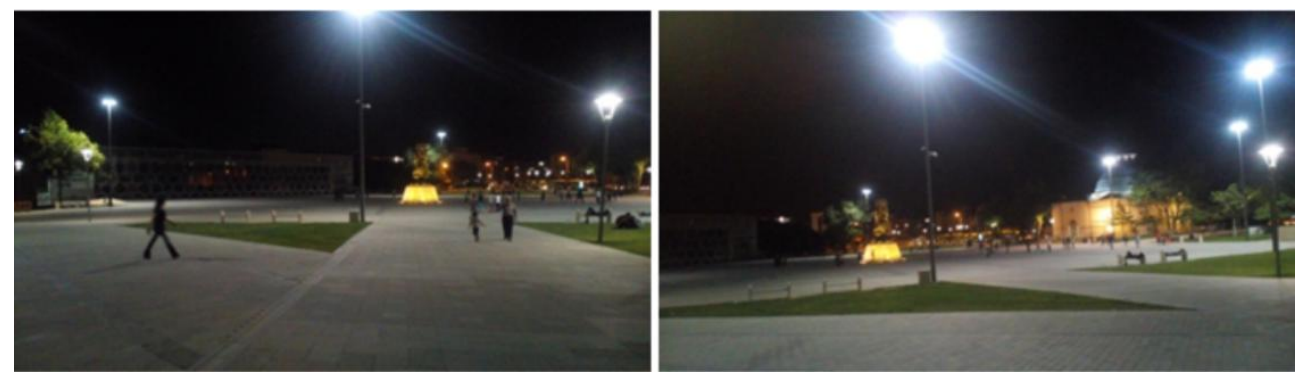

Figure 12: General night appearance of Konya City Square.

In order to test the accuracy of the data obtained from the observations carried out on the Square at night, mobility records and syntactic analyses were conducted. The lighting data was tested for accuracy by observing pedestrian movement at particular times and overlapping them with the maps.

\subsection{Choosing the Viewing Point}

First of all, a viewing point and a perspective were chosen to compare user mobility on Konya City Square to the Space Syntax analysis results. Here, a viewing point was selected to the north of the Karatay Museum which had the best visibility of the Square and the highest level of pedestrian mobility. The perspective, on the other hand, was towards both the Square and the Civilization Monument situated at the center of the Square. Furthermore, the main islands were named with symbolic letters in the study for easier description of axes and spaces (Figure 13).

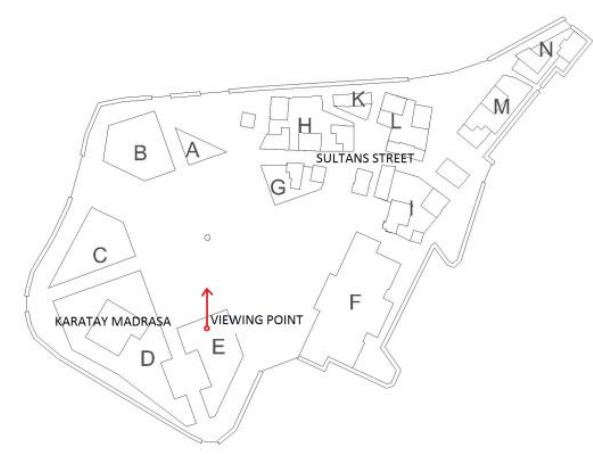

Figure 13: City Square Main Islands and Viewing Point.

\subsection{Mobility Record}

Between January 15-21, 2016, records were kept over one week at the selected viewing point, both on weekdays and at the weekend, and user mobility was tracked. The fact that the daytime temperatures on these record dates were above seasonal norms on certain days (approximately $10 \mathrm{C}$ and higher), and that it was rainy on the others, 
increased the record diversity. One night on the weekday, the power of the Square was turned off in order to heighten the difference, and this case was evaluated in the user mobility analysis.

Actually in summer days it is expected to be much higher the diversity of square than in winter days according to weather conditions. But the schools are off and because of summer holiday the diversity of square is as same as January in June.

Accordingly, the obtained data were archived and transformed into five-minute displays grouped as follows:

1. Between 05:00 - 11:00 a.m. on weekdays.

2. Between 04:00 - 08:00 p.m. on weekdays.

3. Between 12:00 - 05:30 p.m. at the weekend.

4. Without electricity, between 02:00 - 07:00 p.m. on weekdays.

5. Rainy weather in the daytime.
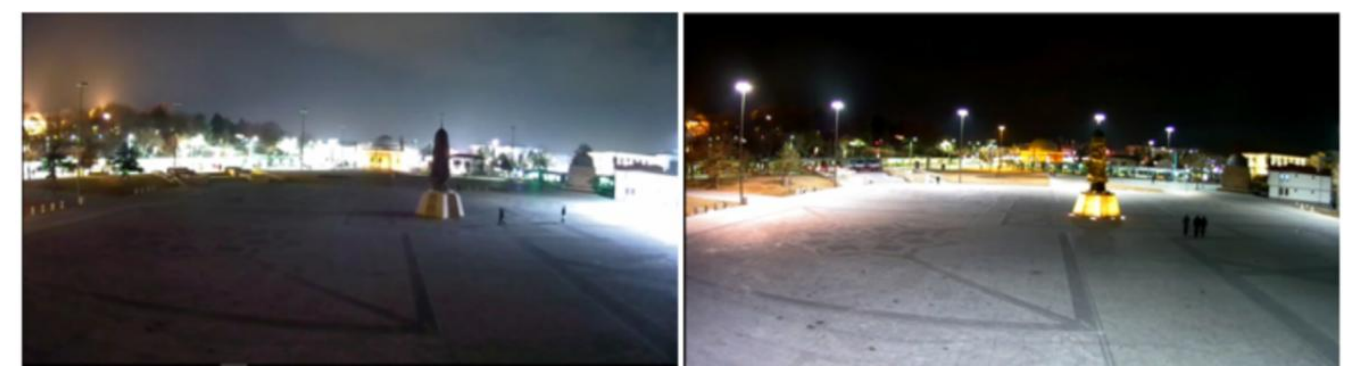

Figure 14: Pedestrian movement records at night with and without square lighting
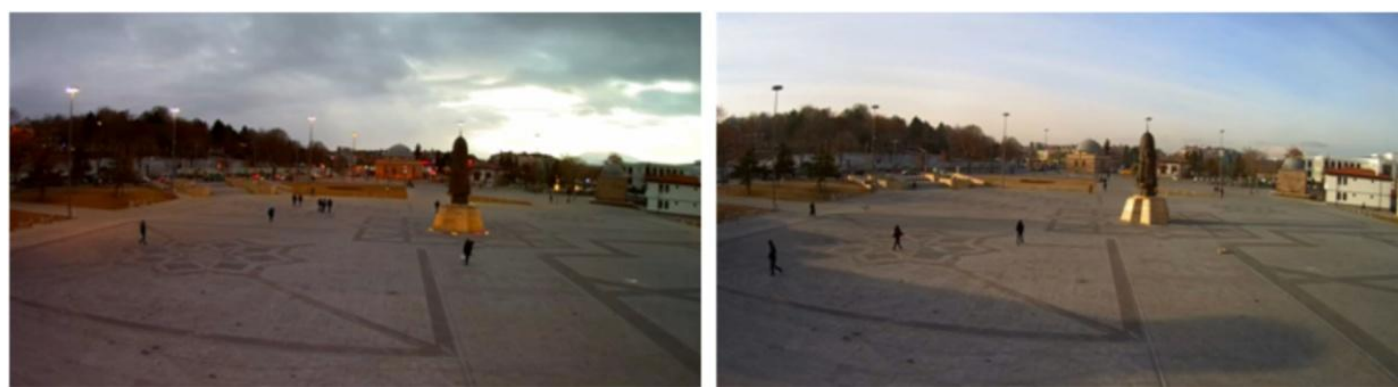

Figure 15: Pedestrian movement records in different times of day
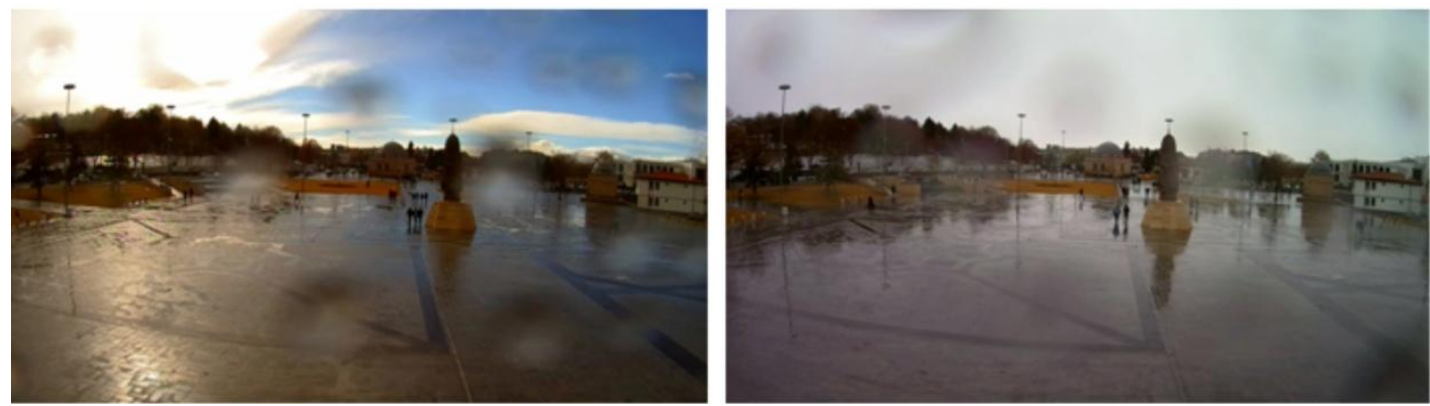

Figure 16: Pedestrian movement records in rainy day
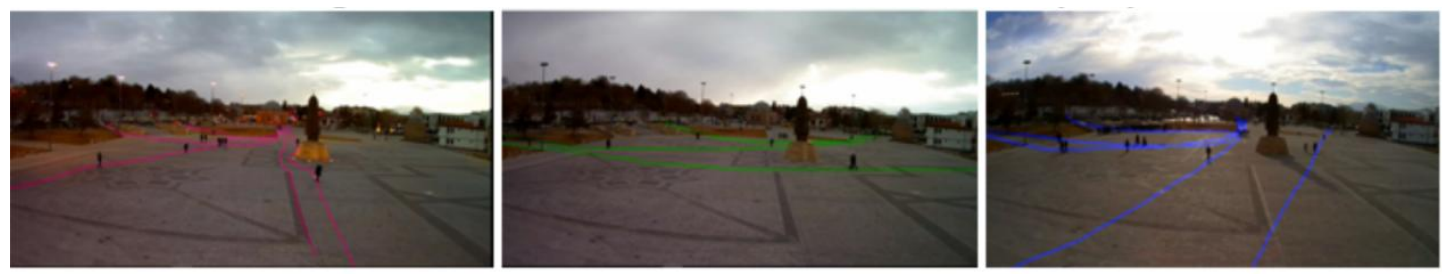

Figure 17: Pedestrian movements in different axes 


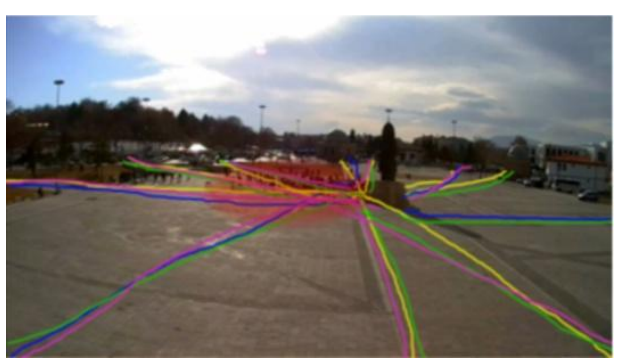

Figure 18: Pedestrian movements axes and meeting point of square

\subsection{The Axis Map}

One of the most consistent findings of the Space Syntax analyses is that the textures of pedestrian movement and vehicle movement in the urban areas, the land use, and the crime ratio in the housing zones, have a direct and considerable relation to the city structure and its spatial order.

The essential computer modeling technique is the "Axial Map", which enables the numerical estimation of movement potentials, land-use textures and a feeling of insecurity. Axial maps are obtained by drawing roads on the current maps which give access to pedestrians using the longest possible "lines." The length of these lines, which are also called "lines of sight," and connections they made with the other lines, determine the results of the axial map. In this calculation, a software application developed for the Space Syntax model (UCL, Depth map) was used (Özer 2016).

For the axial map study carried out on Konya City Square, the directions used by the pedestrians were determined and the longest pedestrian movements were processed on the map using the Depth map software. The "all axes" map, which was obtained, is observed in Figure 19.

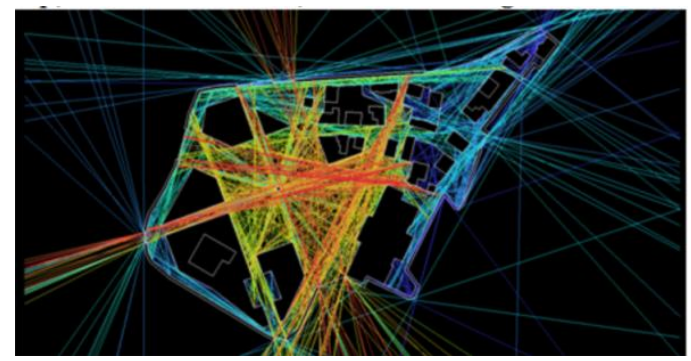

Figure 19: City Square All Axes Map.

(The color red indicates the highest integration value. The integration values are indicated in red, orange, yellow, green, cyan, and blue respectively)

\subsection{Spatial integration}

The lines on the axial map were processed in the computer program and then used in determining the pedestriandrawing potential of the space. At the end of this process, the program gives an "integration value" for each of these lines. Some axes on the map are more suitable for reaching another place (axis) in the working area. The accessibility of these axes is higher. In other words, they are "more integrated" axes. The axes with low integration values have a lower accessibility. These axes are "separated" as well.

The shortest route between two points within the area passes through the axis, the integration value of which is the highest between those two points. These integration values can transformed into colored thematic maps on computer. The colored graphics allow for understanding at a glance, how a change in design might impact on integration values (Çil 2006).

\subsection{Estimation of Natural Motion}

Research shows that the integration values provide a reliable estimation of both existent and potential pedestrian movement levels. As stated before, the movement which is handled irrespective of other factors, such as the spatial formation is called "natural motion" (Tuncer 2010). 
"Motion Economy" argues that there is a strong relation between pedestrian movement and the spatial formation, and thatthis relation tends to increase. It is because the axes that apply natural motion at a city center will lead to the utilization of land developed in spaces where pedestrians are intensely present (trade, entertainment, refreshment venues, and other urban reinforcements) due to this motion. The relation between the pedestrianmovement ratios and land use gains importance at this point. As the pedestrian-movement ratios are high, the land uses placed here will draw more pedestrians and in this case will have an increasing effect on these movement ratios. The process created by this interaction is called "motion economy"(Tuncer 2010).

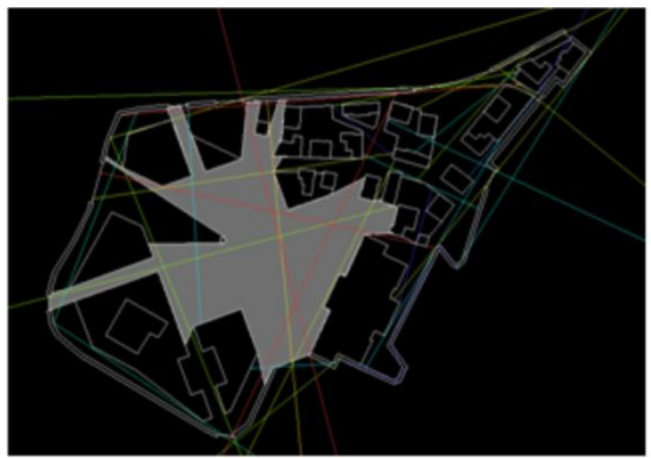

Figure 20: City Square Convex Spaces and Minimal Axes.

It is evident that the longest and the uninterrupted connection visible from the working area surroundings will draw more pedestrians compared to other options. The reason for this case is that people always prefer the shortest route to wherever they would like to go. The movement which occurs along this route will also create an effect that will integrate these areas with the other areas of the city.

Meeting points in which people meet their friends or families, visit their neighbours and greet each other or even have easy relationships with foreign people,(Aykal, Erbaş, Baran 2017, 319) so the connection and meeting points are important in squares. When the City Square is also examined in terms of connectedness values of the Space Syntax Method, integration value and mean depth values, the following tables emerge.

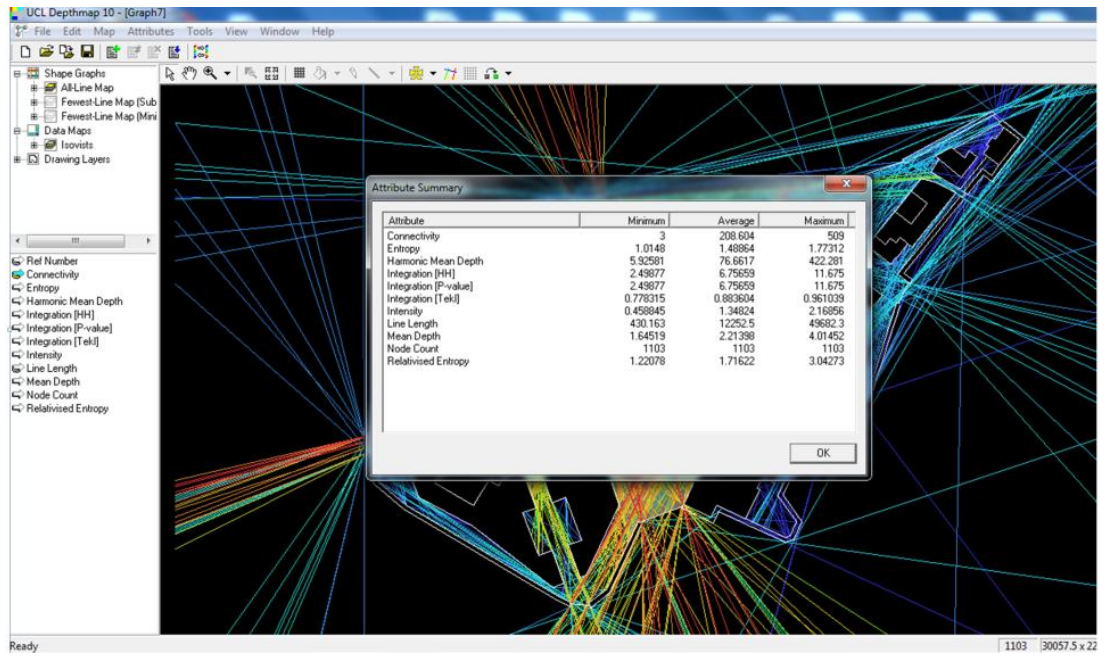

Figure 21: City Square Space Syntax Analysis Values.

In conclusion, the Space Syntax Method, searching for the relation between pedestrian movement and the spatial formation, gives highly consistent results. It argues that the longest and the uninterrupted connection will draw more pedestrians compared to other options. This movement will create an effect that will integrate these areas with the other areas of the city. 


\subsection{Lighting Values}

A lighting analysis was also conducted in the City Square using the DIALux lighting calculation program and was found to be consistent with the current records. Here, dimming was applied from the east, north and west sides of the civilization monument located in the middle of the Square to create a shading effect in the middle of the Square and to highlight the Civilization Monument under this shading effect with its own customized illumination. (Figures 22, 23)

But as there is no visual or sensory relevant epigraph available on or around the monument here, the users feel the open space. As may be observed from the weekend displays, this is a Square that is capable of allowing for many physical activities; however, the mass at the center of the Square is poorly defined.

Furthermore, due to the functionality and the density of the Square, no change is observed in user mobility whether it is rainy or the power is off.

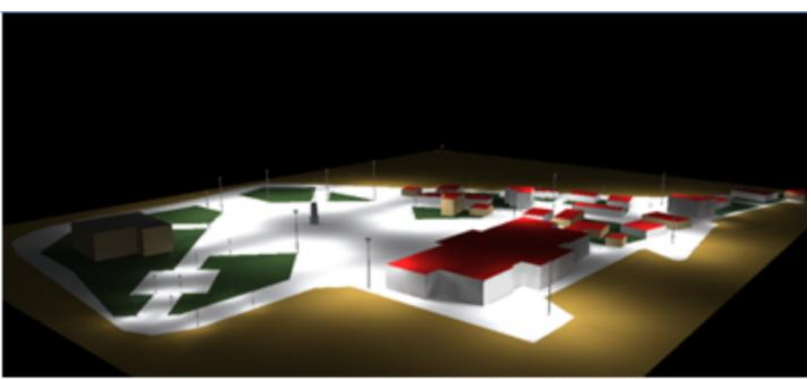

Figure 22: City Square Visible Lighting Analysis via DIALux (Gray Scale).

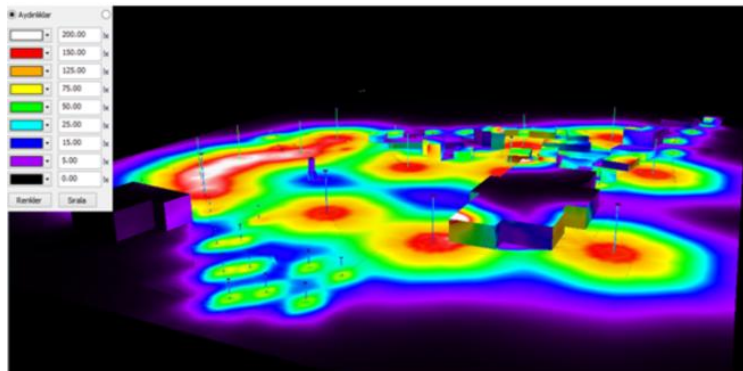

Figure 23: City Square Lighting Values via DIALux (Unit: Lux).

The existing lighting devices (luminaires) used in the square are selected carefully used in the programme DIALux. The brightness level in the simulation results are compatible with the brightness levels in the square according to orientation factor and video records. It is seen that the light from the monument's high-mast lighting devices is illuminated by the light from the devices buried in the floor around the monument's quasi-monument. This illumination is poor and weak so the presence of embedded devices in the modelling is not considered.

Table 1: The comparision of 3 analysis of square according to density, axl and monument.

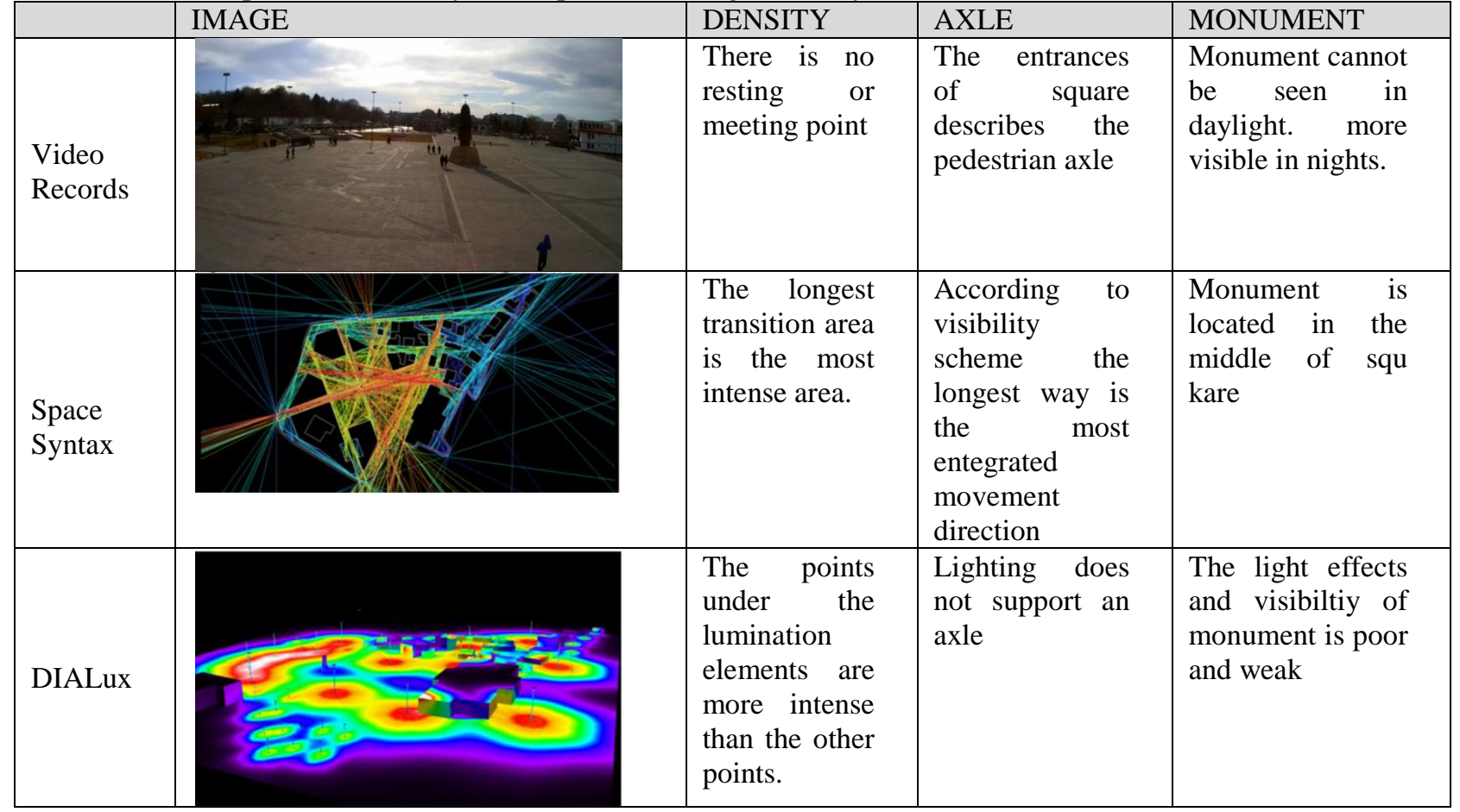




\section{CONCLUSION AND RECOMMENDATION}

In conclusion, not many contradictions were observed between the analyses and the applications when the City Square lighting practices effects on urban life and user mobility were examined. However, the Civilization Monument, in the middle of the Square, should have greater emphasis with an appropriate lighting design to reveal its semantic value. The uncertainty about the direction users in the Square will follow eliminates the effect of the Square. In this context, routing elements should be employed to allow users to spend quality time in the Square. User mobility can be directed with visual and auditory epigraphs that can be situated in an appropriate place to emphasize the monument in the daytime. The monument can gain a different meaning with luminous effects at night. Examples of this in several squares are as follows:

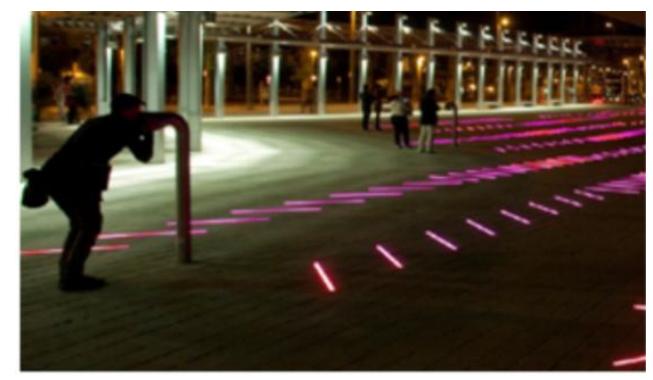

Figure 24: Spain - Barcelona - Bruum Ruum7

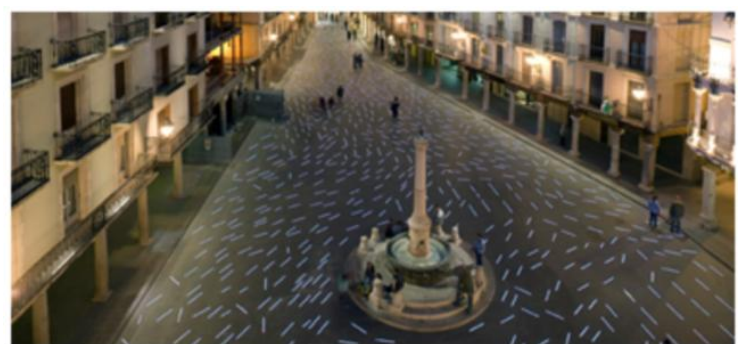

Figure 25: Spain - Torico - Plaza del Torico.

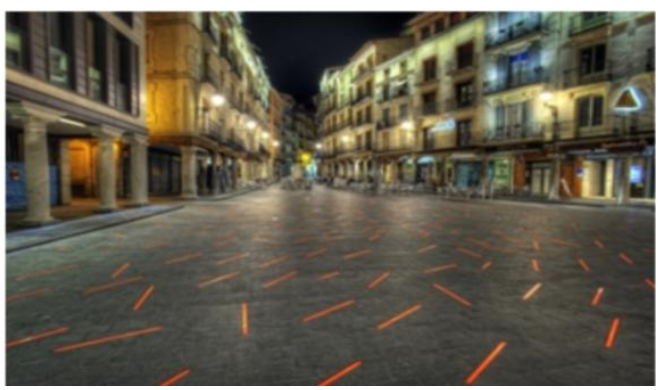

Figure 26: Spain - Torico - Plaza del Torico.8

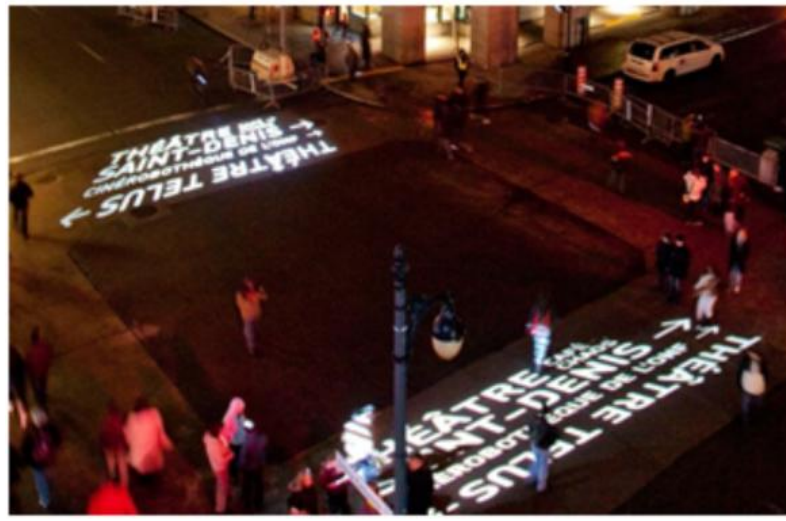

Figure 27: Canada - Montreal-Quartier des Spectacles.

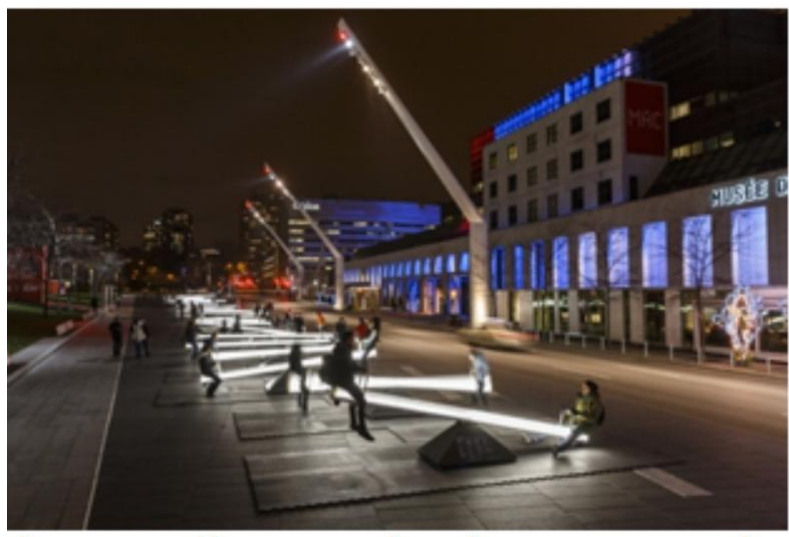

Figure 28: Montreal Square illuminated and interactive urban furnishings.

The recommendations and arrangements for the Square and the Civilization Monument will gain much more significance by the time the Selçuklu Exhibition Center, located to the north of the City Square, is completed and as soon as the constructions on Sultan Street situated in the northwest, go into service.

The study foundations:

- User mobility on the Square is in compliance with the Square arrangement; however, user densities and therefore the lighting differences are not identified due to the incomplete constructions. 
- The Square transfers the pedestrian axes in the neighborhood to the right points, but the routing effects of the floor and the lighting elements are low. Thus, a sense of open space, and nondefinability are common on the Square.

- The monument at the center of the Square is not visible enough in terms of semantic and functional value. Pedestrian axes and lighting solutions specific to assembly and stopover points should be conducted. Moreover, the monument's own lighting should be revised.

- Interactive and entertainment lighting systems and urban furnishing reinforcements can be utilized in order to reduce the width of the Square and the sense of open space, improve the usability of the Square and allow users to enjoy it more actively and efficiently.

\section{REFERENCES}

[1] DOKUZCAN H. 2006, Urban Lighting and Taksim Square according Lighting Bahçeşehir University, Master Thesis. İstanbul

[2] ÖZDEMIR E.E. 2016, Deneyimle Değişen Kentsel Mekan Algisi Ve Kent İmaji: Mimarlik Ve Mühendislik Öğrencileri Örneği, Doi: 10.17365/TMD.2016716508, Uluslararasi Hakemli Tasarim ve Mimarlik Dergisi Y1l:2016 Sayı: 7 Alan: Mimarlık

[3] TS EN 12464-1. Light and lighting - lighting of work places - Part 1: Indoor work places,

[4] ISO 8995-1:2002(en) Lighting of work places — Part 1: Indoor

[5] YILMAZ ÇAKMAK B., The Change in Space in the Context of Migration in Process of Rural to Urban , Çizgi Publications, ISBN: 978-605-4451-69-2, pages 151 Konya, 2011

[6] TUNCER, E, "Is Space Syntax enough to read space? Default Technique", Arredamento Architecture 242, pages. 114119, december 2010.

[7] AYKAL F, ERBAŞ M., BARAN M.,2017, Kent Parklarinin Evrensel Kalite Kriterlerine Göre Değerlendirilmesi; Diyarbakir Örneği, Uluslararasi Hakemli Tasarim ve Mimarlik Dergisi Yı1:2017 Sayı: 10 Doi: 10.17365/TMD.2017.1.007.x

[8] ÖZER Ö. - The Relation of Pedestrian Movements and Space, Space Syntax Methodology- İstanbul Technical University, Urban Design Master Programme 2016.

[9] ÇIL E.. Theoretical And Methodological Discussion Of The Space Syntax Analysis As A Tool For Reading The City. Megaron. 2006; 1(4): 218-233 